\title{
The Research of Vocational Qualification Factors in Higher Vocational Colleges fresh Teachers
}

\author{
Liu Yang ${ }^{1}$ \\ ${ }^{1}$ Wuhan City Vocational College, Wuhan, Hubei Province, China
}

Keywords: Higher vocational colleges, the new teacher, Qualification, Factors

\begin{abstract}
Carrying out the vocational qualification certificate system in higher vocational colleges is also exist only quantity, not heavy quality and professional standards has yet to organic teaching system and so on. Higher vocational colleges should seriously reflect on and avoid blindly pursue "double the rate", completes the system design, promote the reform of the whole, carefully selected appropriate professional qualification elements, actively participate in the development of new professional standards, constructs the course system of professional qualification, the professional elements in organic integration of the qualification.
\end{abstract}

\section{Introduction}

At present, the administrative department of education for teachers "double teacher quality" has been defined, but for the "double type" teachers' qualifications ordinance has not issued a formal recognition, most vocational colleges are formulated according to the requirement of "double type" teachers' qualifications, examination and evaluation method. Based on this, the qualification cognizance of the "double division type" teacher way is to use "ordinary undergraduate course standard", more emphasis on teacher's academic level, and neglected the evaluation of higher vocational teachers' practical ability, higher vocational education teachers lack title appraisal and characteristics [1]. How to build a targeted and operability of the "double type" teachers' qualification, inspection and evaluation standards, the key is we want to analyze the index system of positioning, and then to the weight of each index for scientific allocation, finally was able to make the "double type" teachers' qualification, examination and evaluation to achieve the purpose of refinement, quantifiable.

\section{Internal problems in the process of implementation of professional qualification certificate system of vocational colleges}

Higher vocational colleges comprehensive, in-depth implementation of professional qualification certificate system, is faced with the external environment problems, is faced with internal problems. Literature in recent years, the study of the external environment problem more and more scholars mention problems include: card from different departments, research market chaos, enforcement employment admittance system, the types of certificates is not complete, professional standards development and revision is well behind states such as career development and the progress of technology enterprises. In view of the research has been more thoroughly, this article mainly analyzes the internal two prominent problems of higher vocational colleges [1].

One-sided pursuit of "double the rate", pay attention to quantity, not quality. Some schools and professional one-sided pursuit of "double the rate", do not take the quality when choosing the professional qualification certificate, there are two typical forms:

One is allowed. Some schools, professional in the talent training scheme of professional qualification certificate of scope is very broad, and a professional corresponds to more than 10 professional qualification certificate, and do not ask whether this certificate correspond to the student's goal post, even some professional just abstractly ask students must have at least one the professional qualification certificates [2]. Some schools the same kinds of different types of vocational qualification certificates issued by the professional basic same, specialized and professional correspondence is not strong, the difference between professional and professional 
reflect not to come out. Even if the student to obtain the professional qualification certificate is contact with the professional is not tight, doesn't even relevant, graduated also be holding a "double certificate". The result is improved card "dual rate", but the talent training quality has not been improved.

Another kind is deliberately. Some kinds of in a variety of corresponding professional qualification certificate of the professional to choose from, choose high pass rate, easy to get the certificate as a requirement for students; Have a plenty of level [2]. In terms of the same kind of professional qualification certificate, high level of affirmation test is more difficult than the low level. Higher vocational colleges at present, including most of nation-level model vocational colleges require students to obtain the intermediate certificate, equivalent to secondary vocational and technical school, very few graduates to obtain the proportion of senior certificate, higher vocational colleges and secondary vocational level difference.

Professional standards have not yet organic into the teaching system. Although each are all in the implementation of professional qualification certificate system in higher vocational colleges, rarely consider the requirements of professional standards; School curriculum system according to the professional standards of adjustment is not in place, many higher vocational colleges is to increase a few door outside the original curriculum system research training courses, namely in the professional teaching of spare some time for the student to carry on the short-term vocational qualification certificate examination training, training students to purchase textbooks, an additional class time, adding to the already so the burden of students, and the waste of manpower and time [3]. The teaching content, especially professional teaching material can not cover the requirements of professional standards; Teachers do not meet the requirements for education of professional qualification certificate, and some specialized course teachers lack of professional standards requirements can be incorporated into the consciousness of professional teaching, some specialized course teachers still not familiar with the requirements of professional standards, some specialized course teachers' teaching method is not adapt to the requirement of professional qualification training.

\section{The qualification cognizance of the senior vocational colleges in teachers' professional study}

Since the "double type" teachers are teachers' qualifications and professional qualification, professional and technical practice of its requirement is can not only teach students how to learn, can teach students how to do it again, outstanding ability education as the standard, the practice teaching of teachers of vocational education. Put forward of the concept of "double type" teachers is to emphasize the importance of practical teaching, to promote the combination of theory teaching and practice teaching. Therefore, for the "double type" teachers' qualification we should have the skills assessment as an important index decrease the academic requirements [3]. Currently, many higher vocational colleges in the nation according to the education situation and the trend of economic development, and connecting with the social demand for advanced application-oriented talents, make full use of local advantages, suitable for their own situation to make some of the "double division type" teacher qualification standards, good results have been achieved.

Theoretical basis for teachers' assessment and evaluation system. Higher vocational college "double type" teachers' assessment and evaluation system belongs to the category of the soft science. Soft science is the basic requirements of the complexity of the decision-making and management practice, systemic project, and use modern means of science and technology is proposed to choose from a variety of approaches, methods, measures and countermeasures, makes management and decision-making scientific basis and process of system guarantee, so as to realize efficient, scientific and modern management and decisions [3]. Higher vocational college "double type" teachers assessment and evaluation mechanism for the improvement of the "double type" teachers' access system and complementary, which can effectively control and guide the "double type" teachers act, play a role of higher vocational college teachers' teaching and research work such as the baton, and then drive to achieve the goal of the whole school.

Teachers assessment and evaluation system based on reality. 87 professional regulations in China, in view of the various professional teachers with professional have the difference, each 
professional qualification certificate in accordance with the five hierarchy, such as most mechanical professional teachers have professional qualification certificate, but in the early, middle and senior technician in existence very big difference on the professional level, if the teachers agreed unanimously to the "double division type", it is unfair. How to develop a more detailed measures for the "double division type" teacher evaluation of the most effective approach is to build the "double type" teachers' professional qualification standards, the formation of "double type" teachers review sequence, "double type" teachers can be divided into primary, intermediate, advanced, and it is not only beneficial to the construction of "double type" teachers' professional development echelon, but also a kind of "double type" teachers' incentives, can reflect the "double division type" teacher training of long-term mechanism [4]. At the same time, we also should consider the efficiency of the "double type" teachers' qualification certificate, "double type" teachers' qualification certificate of the gain is not a one-off, more is not for life, it is necessary to regularly update and maintenance, which facilitates the "double type" teachers' ability of sustainable development.

Higher vocational college "double type" teachers assessment and evaluation system. Higher vocational college "double type" teachers assessment and evaluation system mainly includes the appraisal and evaluation target, evaluation and evaluation subject, evaluation and evaluation objects, evaluation and evaluation index, evaluation and evaluation methods, evaluation and evaluation content, evaluation and assessment standard seven aspects [4]:

1) the inspection and evaluation target: higher vocational college "double type" teachers assessment and evaluation target from belongs to the total development strategy target in higher vocational colleges, higher vocational education needs through the teacher's teaching quality to ensure quality, the "double type" teachers teaching process monitoring is helpful to achieve the goal of higher vocational education teaching effectively.

2) assessment and evaluation subject: higher vocational college "double type" teachers assessment and evaluation main body is a key part of the assessment and evaluation can be effective, including the departments, the department in charge of teaching, experiment practice unit, colleagues, students and other personnel assessment, evaluation subject also must have the corresponding ability of index measurement, assessment and evaluation objects accordingly so as to comprehensively and objectively reflect the actual effect of the teacher, the appraisal result to convince people.

3) assessment and evaluation objects, evaluation and evaluation objects "double type" teachers in higher vocational colleges.

4) the inspection and evaluation indexes, through the examination and evaluation contents determine the corresponding index units and units of different weights are given, which reflects the assessment and evaluation purposes, and it is concluded that the inspection and comprehensive performance evaluation objects.

5) the assessment and evaluation methods: higher vocational college "double type" teachers assessment and evaluation is the core issue of multi-index comprehensive evaluation, the assessment and selection of evaluation methods and scientific, comprehensive, rationality determines the appraisal and evaluation of comprehensive, objective, accurate and fair.

6) the inspection and evaluation content: the appraisal and evaluation content mainly refers to the specific "double type" teachers in higher vocational colleges what aspects of the implementation of the assessment and evaluation. This topic appraisal and evaluation content involves ethics, teaching, scientific research, discipline construction, social service, and talent cultivation and so on.

7) the inspection and evaluation standards "means to determine higher vocational" double type "teachers' comprehensive performance frame of reference and reference point, the inspection and evaluation standards depends on the assessment and evaluation purposes.

Construction of higher vocational college "double type" teachers assessment and evaluation factors. Higher vocational college "double type" teachers assessment and evaluation system model is a complete assessment and evaluation index and scientific examination and evaluation method of directly determines whether the objective and comprehensive appraisal and evaluation results. Higher vocational college "double type" teachers assessment and evaluation system to establish the scientific directly decide the result of examination and evaluation, the assessment and evaluation index is 
composed of multiple elements, and each element is a system associated with each other, thus constitute a comprehensive evaluation index system [3]. Assessment and evaluation system generally can be divided into several levels, the logical order should be: system, subsystem, primary, secondary, tertiary indicators and so on.

How the higher vocational college "double type" teachers' teaching quality and research level and social services to make scientific, accurate, comprehensive assessment and evaluation in higher vocational colleges is the "double type" teachers team construction of an important and difficult. Due to differences in academic research achievements, professional differences, reflect in the form of differences, differences in the levels of understanding, etc. , it is difficult to find a universally applicable to all teachers assessment and evaluation standards. Therefore, higher vocational colleges to build "double type" teachers assessment and evaluation system is a complex issue, its assessment and evaluation have the characteristics of relativity. In addition, the higher vocational college "double type" teachers' assessment and evaluation should combine virtue, talent training, service society implicit indicators, fully considering the higher vocational college "double type" teachers assessment and evaluation of comprehensive, multidimensional nature characteristics.

Goal-directed factors. Higher vocational college "double type" teachers' evaluation and selection of evaluation indexes and design must pay attention to the combination of school development strategic target, the right of the establishment of the indicators and important to be able to reflect the school in different periods, different development phase of the strategic objectives and priorities [2]. Should give the assessment and evaluation system of examination, constraint function, also should pay attention to the teacher's guidance, incentives, to refine the school's strategic development target for each direction of "double type" teachers' work, to excite the work enthusiasms of "double type" teachers.

Systemic factors. Higher vocational college "double type" teachers' assessment and evaluation system building needs to focus on three aspects of content. First of all, to consider the dominant and recessive, and the organic combination between the qualitative indexes and quantitative indexes, so as to obtain the objective, systematic and comprehensive assessment and evaluation results; Second to coordinate all inspection and evaluation index, for each indicator elements to make overall arrangement and consideration, can reflect in higher vocational colleges to "double type" teachers' professional quality, work performance, work process, and many other aspects of the assessment and evaluation [3]. Again, should be consider different levels and different subjects of "double type" teachers' characteristics and differences, such as basic subjects and professional disciplines and the difference between humanities and science, the "double type" teachers assessment and evaluation to achieve the combination of quantity and quality, and the combination of qualitative and quantitative.

Operational factors. Maneuverability principle for assessment and evaluation system as far as possible the indicators can be collection, quantifiable and can be compared, to clear the "double type" teachers' works requirements, to facilitate management by objectives. In addition, quantitative and conducive to the transverse comparison of "double type" teachers and statistics, for the assessment, title promotion and teacher appraisal and provide objective basis [1]. In particular, the "double type" teachers' labor including teaching, scientific research, discipline construction, virtue, talent training and social service six aspects, these elements constitute a linked complex, long-term and dynamic process, it involves a lot of difficult to measure the content of the refinement indicators, this needs us to make the definition of each indicator possesses more accurate, so as to ensure the scientific of quantitative evaluation.

Dynamic factors. "Double type" teachers are a dynamic concept, the need to "double type" teachers implement dynamic management. With advances in science and technology, in a timely manner to meet teachers update and absorb the theory knowledge, technology, process specification and technology method, is to ensure that the effective way to teachers' knowledge structure, ability structure often new [4]. For the "double type" teachers' evaluation should be submitted to the school regularly "double type" teachers construction committee review, the teacher, there is no objection on the publish of dispatch confirmation for the annual "double type" teachers, and formulate reasonable 
fixed number of year, the validity of "double type" teachers to optimize the construction of "double type" teachers.

The system structure and weight distribution factors. For a long time, the higher vocational college "double type" teachers' assessment and evaluation mainly adopts "qualitative" and "quantitative" assessment method, combining the teachers' political quality, professional level, teaching, scientific research, social service, etc [3]. Usually to the evaluation of teachers' political quality is given priority to with qualitative analysis, for teaching and scientific research is focused on the quantitative evaluation, the assessment is based on teacher's teaching, scientific research and other work performance.

\section{Summary}

In higher vocational colleges professional qualification examination and evaluation system structure weight, the major factors involved is a three-level index, each level index connotation clear, are endowed with corresponding weight value, has good scalability, if choose appropriate measurement, statistical methods, it is possible to obtain comprehensive evaluation score and more reliable conclusions, and quantitative decision evaluation conclusions.

\section{References}

[1] Sh. F. Li, Theory of new upgraded "double type" teaching team construction in higher vocational colleges - certain vocational and technical college as a case study, Beijing: central university for nationalities, 2010, vol. 5, pp. 41-45.

[2] Ch. Y. Zhou, Complexity in the perspective of university teachers' performance appraisal research, Zhenjiang Jiangsu University, 2009, vol. 2, pp. 12-16.

[3] X. M. Ye, Teaching staff construction in higher vocational colleges in Guangdong, Guangzhou: Guangdong higher education press, 2014, vol. 6, pp. 34-37. .

[4] M. Q. Li, Double system to cultivate teachers' research, Wuhan: Huazhong University of science and technology press, 2012, vol. 3, pp. 32-36. 